\title{
A pilot integrated qualification program to improve medication use in a long-term care facility: a hybrid effectiveness-implementation study
}

\author{
Felipe Augusto dos Santos Oliveira Lima ${ }^{1,2}$ (1), Mariana Martins Gonzaga do Nascimento ${ }^{2,3 *}$ (1) \\ Cristiane de Paula Rezende ${ }^{1,2}$ (1) , Marina Dias dos Santos ${ }^{4}$, Luciana Raid Farnese ${ }^{4}$, \\ Samilla Dornellas Faria ${ }^{4}$, Aline Silva de Assis Santos ${ }^{1,2}$ (D), Sabrina Gonçalves Ferreira² (D), \\ Gabriela Oliveira Buzelin Doria² (1D), Djenane Ramalho-de-Oliveira ${ }^{2,5}$ (1)
}

\author{
'Programa de Pós-graduação em Medicamentos e Assistência Farmacêutica (PPGMAF), Universidade Federal de Minas Gerais \\ (UFMG), Belo Horizonte, MG, Brasil \\ ${ }^{2}$ Centro de Estudos em Atenção Farmacêutica, Faculdade de Farmácia, Universidade Federal de Minas Gerais (UFMG), Belo \\ Horizonte, MG, Brasil \\ ${ }^{3}$ Departamento de Produtos Farmacêuticos (DPFA), Faculdade de Farmácia, Universidade Federal de Minas Gerais (UFMG), \\ Belo Horizonte, MG, Brasil. \\ ${ }^{4}$ Far-me Farmacoterapia Otimizada, Belo Horizonte, MG, Brasil \\ ${ }^{5}$ Departamento de Farmácia Social (DPFA), Faculdade de Farmácia, Universidade Federal de Minas Gerais (UFMG), Belo \\ Horizonte, MG, Brasil \\ *Corresponding author: marianamgn@yahoo.com.br
}

\begin{abstract}
Objective: to describe the implementation and to assess the effectiveness of a pilot integrated qualification program to improve the medication use in a long-term care facility (LTCF). Methods: This was a type 1 hybrid effectiveness-implementation study. A pilot integrated qualification program to improve the medication use in a LTCF was carried out by implementing a new drug distribution system and a comprehensive medication management (CMM) service according to the following four steps: I) implementation of the drug distribution system followed by the evaluation of the health team's opinion; II) prescription review with the identification of potential drug therapy problems (PDTPs); III) provision of the CMM service according to the framework of Pharmaceutical Care practice within one year; and, IV) evaluation of the effectiveness of the program through the comparison of clinical and laboratory parameters (blood pressure, glycated hemoglobin and lipid fractions) using the t-test or Wilcoxon signed-rank test. Results: In step I, the distribution system was fully outsourced to a company that furnished all solid oral dosage forms in individual boxes containing a plastic coil with multiple envelopes for 30 days. In step II, 180 PDTPs were identified, and all patients presented with at least one of them. In step III, after the first assessment of the CMM Service, 43 actual drug therapy problems (DTPs) were identified. After one year of service provision, 96 DTPs were identified and $75.8 \%$ of them were resolved $(n=72)$. In step IV, a statistically significant difference was observed between the initial and final minimum and maximum systolic and diastolic blood pressure $(p<0,05)$. Conclusions: The pilot integrated qualification program had a positive impact on the clinical parameters. The global population is rapidly aging, making this type of study important to exemplify a multifaceted strategy to improve the quality of drug therapy for institutionalized patients.
\end{abstract}

Keywords: Aged. Medication Systems. Implementation Science. Medication Therapy Management. Long-term Care.

Financial support: FASOL and CPR - Received scholarship from Coordenação de Aperfeiçoamento de Pessoal de Nível Superior (CAPES). ASAS - Received scholarship from Fundação de Amparo à Pesquisa do Estado de Minas Gerais (FAPEMIG). SGF and GOB - Received scholarship from Universidade Federal de Minas Gerais (UFMG). MMGN, MDS, LRF, SDF and DRO - none.

Conflicts of interest: The authors declare no conflict of interest.

The study was carried out at Federal University of Minas Gerais (UFMG), Belo Horizonte, MG, Brasil.

Received on December 02, 2021. Accepted on January 29, 2022. 


\section{How to cite}

Lima FASO, Nascimento MMG, Rezende CP, Santos MD, Farnese LR, Faria SD, Santos ASA,

Ferreira SG, Doria GOB. A pilot integrated qualification program to improve medication use in a long-term care facility: a hybrid effectiveness-implementation study. Rev Ciênc Farm Básica Apl. 2022;43:e772. https://doi.org/10.4322/2179-443X.0772

\section{INTRODUCTION}

The aging of the global and Brazilian population increases the prevalence of chronic non transmissible diseases, such as cardiovascular diseases, diabetes and dementia, which, consequently, decreases functional and cognitive capacities ${ }^{1}$. These factors contribute to the institutionalization of older adults in long-term care facilities (LTCFs), where more fragile patients are often exposed to higher number of medications and drug-related risks ${ }^{2,3}$. In Brazil, it is estimated that $1 \%$ of the older adult population lives in about 3.600 LTCF, with a quarter of these been private institutions ${ }^{4}$. However, little is known about the health or medication use profile of institutionalized Brazilian patients ${ }^{3,4}$.

A previous systematic review showed that $91 \%$ of the older adults living in LTCFs continuously used more than five drugs, while $65 \%$ used more than ten drugs ${ }^{3}$. Polypharmacy may predispose older patients to a greater risk of drug interactions (DIs), use of potentially inappropriate medications (PIMs) and adverse drug events. It may also increase morbidity, mortality and the complexity of care ${ }^{5-7}$.

In this context, it is important to improve the quality of the medication use processes in LTCFs. To this end, it should involve the improvement of medication prescription, implementation of safe distribution systems, and provision of evidence-based clinical pharmaceutical services. However, to the best of our knowledge, no study with a broad methodology in the LTCFs context has yet been published. Thus, the present study aimed to describe the implementation and to assess the effectiveness of a pilot integrated qualification program to improve the medication use in a LTCF.

\section{METHODS}

This was a type 1 hybrid effectiveness-implementation study, encouraged by the World Health Organization (WHO) for the evaluation of the impact of "real world" services ${ }^{8,9}$. The study was approved by the Ethics Committee of the Federal University of Minas Gerais (UFMG) (protocol number: CAAE 25780314.4.0000.0149) and drafted according to the Standards for Reporting Implementation Studies (StaRI) statement, a standardized reporting guideline containing 27 items $^{10}$.

This study was conducted in a conveniently selected private LTCF located in Belo Horizonte (Brazil), that had a partnership with the UFMG. All older adults (aged 60 years or more) residing full-time in the facility in April 2019 were included in the present study (study population $=17$ older adults).

The LTCF has a multidisciplinary health team, that includes a physician, nurses, nursing technicians, and others. The availability of this team and economic resources facilitated the implementation of the integrated program. At the time of the study, the prescriptions were valid for one month, and all medications were distributed by the nursing team using a hybrid distribution system: individualized system for solid oral drugs (using plastic boxes with dividers) and a collective system for liquids oral drugs.

A pilot integrated qualification program was implemented in the LTCF to improve medication use according to four subsequent steps.

\section{Step I - Qualification of the Drug Distribution System}

A new unit dose distribution system was implemented for all residents. Its impact was described though interviews conducted by the main researcher with two pharmacists who 
were responsible for implementing such a system, and with the institution's manager, a nurse director responsible for the LTCF, and a nursing technician (stakeholders). The interviews were recorded, transcribed, and analyzed, making it possible to describe the readjustment of the LTCF drug distribution system and the impacts generated.

Step II - Prescription review

A review of all prescription orders written for older adults (aged $\geq 60$ years) residing at the LTCF in April 2019 (population $=\mathrm{N}=17$ ) was performed, with the identification of potential drug therapy problems (PDTP's) as follows: DIs - moderate or important ${ }^{11}$; PIMs - according to the AGS/Beers Criteria, last updated in 201912; and prescribing omissions (POs) - according to START (Screening Tool Alert to Right Treatment), last updated in $2015^{13}$.

The prescription review was performed in duplicate by two pharmacists in an objective manner using the defined references and data reported in the medical records. However, the patient's individual clinical parameters documented in their charts was not evaluated during the prescription review. After individual analyses, the discrepancies between the two pharmacists were discussed until they reached an agreement. The identified PDTPs were classified according to the Pharmacotherapy Workup method (Table 1$)^{14}$. Older patients were also characterized according to sex, age, time of institutionalization, type and number of health conditions, and medications in use.

Table 1 - Description of the potential drug therapy problems (PDTP) identified during the prescription review process.

\begin{tabular}{|c|c|}
\hline PDTP Classification ${ }^{14}$ & Criteria used for identification \\
\hline PDTP 1 - Unnecessary drug therapy & $\begin{array}{l}\text { - Drugs from the AGS/Beers criteria for which there is } \\
\text { no therapeutic indication }{ }^{12} \text { (e.g., when a patient used } \\
\text { proton pump inhibitors for more than eight weeks) }\end{array}$ \\
\hline PDTP 2 - Needs additional drug therapy & $\begin{array}{l}\text { - Drugs from the START tool }{ }^{13} \text { (e.g., when a patient } \\
\text { was diagnosed with Alzheimer's disease as noted in } \\
\text { the medical records but did not use an } \\
\text { acetylcholinesterase inhibitor) }\end{array}$ \\
\hline PDTP 4 - Dosage too low & $\begin{array}{l}\text { - Drug interactions that cause a low dose of a } \\
\text { medication }{ }^{11} \text { (e.g., when a patient used a CYP450 } \\
\text { substrate and a CYP450 inducer) }\end{array}$ \\
\hline PDTP 5 - Adverse drug reaction & $\begin{array}{l}\text { - Drugs from the AGS/Beers Criteria that when used } \\
\text { by older people provides more risks than benefits }{ }^{13} \\
\text { (e.g., when a patient used a benzodiazepine agent). } \\
\text { - Drug interactions that cause adverse drug } \\
\text { reactions }{ }^{11} \text { (e.g., when a patient used two medications } \\
\text { that were nephrotoxic) }\end{array}$ \\
\hline PDTP 6 - Dosage too high & $\begin{array}{l}\text { - Drug interactions that cause a high dose of a } \\
\text { medication }{ }^{11} \text { (e.g., when a patient used a CYP450 } \\
\text { substrate and a CYP450 inhibitor) }\end{array}$ \\
\hline
\end{tabular}

*AGS = American Geriatric Society; START=Screening Tool Alert to Right Treatment

\section{Step III - Provision of the Comprehensive Medication Management (CMM) Service}

The CMM service was provided by four pharmacists and was integrally based on the Pharmaceutical Care Practice's framework ${ }^{14}$. The patients were prioritized according to the number of PDTPs identified in Stage II; that is, patients with a greater number of PDTPs were included in the CMM service first. However, all patients who lived full-time in the LTCF (population $=\mathrm{N}=17$ ) were followed-up after the end of the study period (one year of CMM provision).

For patient evaluation, data obtained from the medical records, interviews, and patient evaluations were used, in addition to the data collected through clinical discussions with the 
physician, nurse, or nursing technicians responsible for patient care. Therefore, all medications used by the older patients were analyzed to identify their indication, effectiveness, safety, and non-adherence; and all health problems were also assessed to detect any untreated condition that required additional drug therapy ${ }^{14}$.

After the individual study about an specific patient was carried by the pharmacist responsible for him/her, each case was discussed by all the pharmacists involved in CMM provision in group. During this group discussion, strategies for the prevention and resolution of the identified real drug therapy problems (DTPs) were outlined. Pharmaceutical interventions were carried out and discussed verbally with the nursing team, responsible physician, and/or patient.

Considering that the care process adopted in the CMM service is cyclical, after each intervention, it was assessed whether the therapeutic objectives had been achieved, and the care plan was continuously readjusted based on the individual patient profile ${ }^{14}$.

The following service's results were described: number of consultations; number of pharmaceutical interventions performed; number and type of real DTPs. The number of pharmaceutical interventions accepted and the number of resolved DTPs were also accessed to evaluate the CMM service implementation.

Step IV - Evaluation of the effectiveness of the pilot integrated program

To assess the effectiveness of the program, the clinical impact was evaluated by comparing the clinical (systolic blood pressure - SBP; diastolic blood pressure - DBP) and laboratory parameters (glycated hemoglobin - HbA1c; Low Density Lipoprotein Cholesterol - LDLc; and Total Cholesterol - TC) measured before (March 2019) and after the CMM provision (March 2020). These measurements were chosen because they reflect the most frequent health problems identified in the study population, namely, cardiovascular diseases and diabetes. The analyses were performed using the t-test or Wilcoxon signed-rank test (level of significance $=5 \%$ ) using Stata ${ }^{\circledR}$.

\section{RESULTS}

Step I - Qualification of the Drug Distribution System

The distribution system was fully outsourced to a company that furnished all solid oral dosage forms in individual boxes containing a plastic coil with multiple envelopes for 30 days (Figure 1). Each envelope contained the solid oral drugs used by the patient for a given administration time, and was duly identified with the date, time and patient's name. The administration times were previously standardized in the LTCF. Oral liquids drugs became of individual use and were identified with the patient's name.

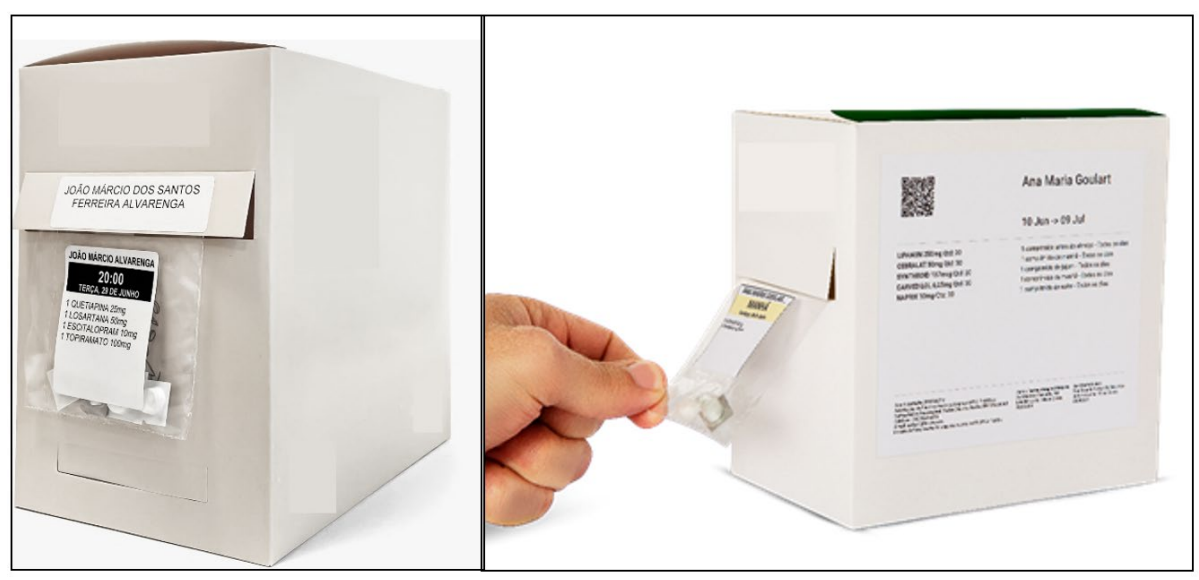

Figure 1 - Individual box with solid oral drugs in unit dose organized according to the time of administration (*fictional names have been used on the box) 
When asked about the impacts of the new distribution system, the manager reported an improvement in the general organization of the LTCF and an increase in the confidence level in the services provided by the management, employees and contracting parties. The nursing team reported an increase in the availability for the provision of health services. The nurse director reported that the system effectively enabled the application of the " 5 rights of medication administration".

Step II: prescription review

A majority of female older adults was identified $(n=14 ; 82.3 \%)$, with an average age of 82.6 \pm 7.6 years and an average of time of institutionalization of $27.2 \pm 15.9$ months. The older adults presented an average of $3.3 \pm 2.4$ diseases and the most frequent diseases were Alzheimer's disease $(n=8)$, followed by depression $(n=7)$ and hypertension $(n=6)$. They used an average of $11.9 \pm 3.8$ medications.

In total, 180 PDTPs were identified, and all the patients presented at least one of them, generating an average of 10.6 \pm 5.5 PDTPs (minimum=6; maximum=27). The most frequent type was PDTP5 ( $n=93 ; 50.8 \%$ - 88 related to DI and 5 to PIM), followed by PDTP4 ( $n=44 ; 24 \%$ all related to DI), PDTP1 ( $n=21 ; 12 \%$ - related to PIM); PDTP6 $(n=12 ; 7 \%$ - related to DI), and PDTP2 ( $n=10 ; 5 \%$ - related to PO).

The most frequent potential DIs involved drugs from the antipsychotic class, totaling 30 interactions (20.8\%), the main ones being between atypical antipsychotics with anticholinesterase drugs ( $n=8$ interactions) and with atypical antidepressants $(n=7)$. Antipsychotics were also the most frequently identified PIMs ( $n=14 ; 53.8 \%$ of the PIM). Meanwhile, the most frequent $P O$ was the need to add an acetylcholinesterase inhibitor in the presence of Alzheimer's Disease ( $n=3 ; 30.0 \%$ of the PO) and the need to add an antihypertensive agent in the presence of hypertension ( $n=3 ; 30.0 \%$ of the PO).

\section{Step III - Provision of the CMM Service}

After the implementation of the CMM service, 43 DTPs were identified in the first consultation; that is, only $23.9 \%$ of the total PDTPs. During the follow-up period, 121 consultations were carried out (mean=7.1 \pm 3.9 ), and 96 DTPs were identified (mean=5.6 \pm 3.4). Patients with the highest number of PDTPs also had a greater number of actual DTPs.

The frequency of DTPs, in decreasing order, was as follows: DTP1 $(n=32 ; 33.3 \%)$, DTP2 $(n=18 ; 18.8 \%)$, DTP5 $(n=17 ; 17.7 \%)$, DTP4 $(n=13 ; 13.5 \%)$ DTP3 $(n=9 ; 9.4 \%)$, and DTP6 $(n=7 ;$ 7.3\%). No DTP7 was identified. Most DTPs ( $n=72 ; 75.8 \%)$ were resolved. To this end, 76 interventions were carried out, most of which were accepted ( $n=66 ; 86.8 \%$ ).

Step IV - Evaluation of the effectiveness of the integrated program

In the Table 2, the initial and final averages of different parameters are presented. However, not all patients had all parameter measurements available for both moments (initial and final evaluations): 12 patients did not have both LDLc tests; 11 did not have both TC tests; 14 did not have both $\mathrm{HbA} 1 \mathrm{c}$ tests. A statistically significant difference was identified between the initial and final minimum and maximum SBP and DBP (Table 2).

Table 2 - Initial and final averages of clinical and laboratory parameters measured. Long-Term Care Facility, Belo Horizonte (MG), 2019-2020.

\begin{tabular}{cccc}
\hline $\begin{array}{c}\text { Parameter (patients } \\
\text { evaluated } \mathbf{n} \text { ) }\end{array}$ & Initial mean \pm SD & Final mean \pm SD & p-value * \\
\hline LDLC (5) & $105.4 \pm 24.4$ & $81.4 \pm 13.0$ & 0.191 \\
TC (6) & $171.0 \pm 25.5$ & $146.7 \pm 13.8$ & 0.174 \\
HbA1c (3) & $6.2 \pm 0.2$ & $6.1 \pm 0.2$ & 0.387 \\
Minimum SBP (17) & $112.4 \pm 3.7$ & $95.0 \pm 3.4$ & $0.004^{* *}$ \\
Maximum SBP (17) & $132.3 \pm 4.2$ & $118.8 \pm 6.1$ & $0.049 * *$ \\
Minimum DBP (17) & $75.9 \pm 5.7$ & $62.8 \pm 1.1$ & $0.017 * *$ \\
Maximum DPB (17) & $92.9 \pm 4.5$ & $77.2 \pm 2.7$ & $0.006 * *$ \\
\hline
\end{tabular}

$\mathrm{SD}=95 \%$ standard deviation; LDLC = low-density lipoprotein cholesterol (mg/dL); HDLc = high-density lipoprotein cholesterol $(\mathrm{mg} / \mathrm{dL}) ; \mathrm{TC}=$ total cholesterol $(\mathrm{mg} / \mathrm{dL}) ; \mathrm{HbA} 1 \mathrm{c}=$ glycated hemoglobin $(\%) ; \mathrm{SBP}=$ systolic blood pressure $(\mathrm{mmHg}) ; \mathrm{DBP}=$ diastolic blood pressure $(\mathrm{mmHg}) .{ }^{*} \mathrm{p}$-value calculated according to the t-test or Wilcoxon signed-rank test; ${ }^{* *}$ p-value statistically significant $<0,05$. 


\section{DISCUSSION}

The pilot integrated qualification program had a positive impact on the clinical parameters. The global population is rapidly aging, making this type of study important to exemplify a multifaceted strategy to qualify the pharmacotherapy of institutionalized patients in LTCFs or other healthcare settings ${ }^{1,3}$.

Qualification of the drug distribution system was important to improve the medication practices in the LTCFs, as signaled by the stakeholders interviewed. In another study conducted in LTCFs in the United Kingdom, $90 \%$ of the residents were exposed to at least one medication error ${ }^{15}$. Errors frequently documented in the LTCFs include wrong time, wrong patient, wrong drug and wrong dose ${ }^{16}$. From this perspective, the new distribution system is believed to be safer because of its potential to reduce such types of errors.

Additionally, adjustments in the distribution system allows the nursing staff to spend more time in providing direct patient care. Studies have shown that nurses spend a substantial amount of time preparing and administering medications; the greater the number of drugs, the greater the time spent ${ }^{17-19}$. In a study conducted in American LTCFs, individualizing doses in a manner similar to that adopted in the present study considerably reduced the time spent preparing the medications ${ }^{19}$. Although the impact on the time spent preparing the medications was not evaluated in our study, the staff indicated greater availability for patient care provision. In addition, considering that the patients used an average of 12 drugs, the new distribution system may have an even greater impact.

Among the identified PDTPs, types 5 (DI that causes an adverse reaction or use of PIM) and 4 (DI that causes a low dose) stood out. This corroborates with the frequent polypharmacy identified, which increases the incidence of Dls. The high prevalence of Alzheimer's disease also contributed to the PDTP, since it increases the use of antipsychotics, which was the drug class most frequently identified as PIM $(n=14)$ or involved in $D I(n=30)$. In a recently published systematic scoping review, use of antipsychotics and cognitive impairment/dementia were, respectively, the drug class and the behavioral disorder most frequently involved in $\mathrm{DI}$ described in explicit PIM criteria-based tools ${ }^{20}$. This finding may have been reflected in the results of the present study.

The use of antipsychotics was considered as a PDTP among $46 \%$ of the older residents in the LTCFs in Europe and Israel ${ }^{21}$. Although they are suited for controlling dementia-related behavioral problems, this drug class should be avoided because of the increased risk of falls, cognitive decline, stroke, cardiac disorders, and mortality ${ }^{12,22-24}$.

These drugs can be used in palliative care ${ }^{25}$, which was the case of 6 out the 11 antipsychotic users in the present study (results not previously reported). Another patient had a psychiatric disorder which required the use of an antipsychotic drug; and for the two other patients, the drug was tapered. For patients who continued to use antipsychotics drugs, DI involving the beforementioned drug, as well as their safety and effectiveness, was continuously monitored. This demonstrates that although the AGS/Beers' Criteria is important for screening PIMs, an individual pharmacotherapeutic evaluation must be caried out when caring for older patients. Also, in the absence of a pharmacological or non-pharmacological alternative, the use of a PIM may be required, but the patient treated with these medications should be closely monitored.

Less than a third of the PDTPs were identified during the initial assessment of the CMM service (43 DTPs were identified; $23.9 \%$ of the PDTPs). By contrast, patients with the highest number of PDTPs also presented more actual DTPs. This finding demonstrates that the prescription review and PDTP identification process serve as important tools for screening and prioritizing patients when implementing the CMM service or when it is not possible to provide the service to all patients.

During the provision of the CMM service, an average of $5.6 \pm 3.4$ actual DTPs per patient was identified. Although, to the best of our knowledge, there are no studies that describe a CMM service in the LTCF setting, studies involving older patients residing in the community identified an average of 3 DTPs per patient ${ }^{26,27}$, which corroborates with the notion that 
institutionalized older people tend to be more complex and thus require more complex medication treatments. Most of the DTPs (75.8\%) were resolved, and most of the interventions were accepted $(86.8 \%)$, demonstrating the good inclusion of the pharmacists in the LTCF healthcare team. However, a limitation of the present study was that the type of pharmaceutical interventions implemented to solve DTPs were not evaluated. Hence, the intervention profile should be considered in future studies to better elucidate the CMM service process in LTCFs.

Despite the higher proportion of PDTPs found to be of type 4 or 5 , during the CMM provision, DTP1 was the most frequent type of actual DTP (33.3\%). A considerable part of DTP1 resulted from the fact that the prescription order prior to the patient's institutionalization was maintained after their admission to the LTCF. Thus, careful pharmacotherapy reevaluation by the pharmacists, including contact with prescribers external to the institution, contributed to its readjustment and medication deprescription. However, during the provision of CMM, DTP7 (non-adherence) was not identified, as all drugs were administered by the nursing staff as prescribed in an organized manner based on the adopted distribution system; moreover, none of the patients refused to use the medications prescribed. In addition, when there was a shortage of certain medications on the market (e.g., the shortage of valsartan and losartan that occurred during the study period), the possibility of changing the medication was individually discussed with the prescriber.

The provision of CMM service had a positive impact on the SBP and DBP. This could reduce the occurrence of important cardiovascular events, especially among complex patients, such as residents of the LTCF under study. For other parameters, it was not possible to verify a statistically significant impact, even though the final values were more favorable than the initial values of all parameters. Missing data due to the absence of laboratory tests or data on medical records, which is a limitation of our study, may have reduced the robustness of the analysis; however, it also reflects the difficulties of a "real world" service. In addition, the impact on other important clinical parameters in the geriatric context, such as mental health scales (e.g., Mini Mental State Examination and Geriatric Depression Scale) was not evaluated in the present study; hence, it should be evaluated in future studies. However, it is important to highlight that, to our knowledge, this was the first study to assess the impact of CMM provision to older patients, and the first to describe this service in a LTCF.

Another limitation of the present study is the absence of external validity regarding its clinical impact. Nevertheless, it demonstrates the feasibility of implementing an integrated medication use qualification program, that proposes, in stages, the continuous improvement of geriatric pharmacotherapy in a LTCF. Its implementation in other LTCFs can potentially change this important and growing scenario.

\section{CONCLUSION}

The pilot integrated qualification program had a positive impact on the clinical parameters. To our knowledge, this was the first study to describe such type of intervention and report the CMM results in a LTCF. The global population is rapidly aging, making this type of study important to exemplify a multifaceted strategy to qualify the pharmacotherapy of institutionalized patients.

\section{REFERENCES}

1. Yokota RTC, Nusselder WJ, Robine JM, Tafforeau J, Deboosere P, Moura L, Andrade SSCA, Castro SS, Van Oyen $\mathrm{H}$. Contribution of chronic conditions to functional limitations using a multinomial outcome: results for the older population in Belgium and Brazil. Arch Public Health. 2017;75(1):68. http://dx.doi.org/10.1186/s13690-017-0235-3. PMid:29270292.

2. Tavares DMS, Pelizaro PB, Pegorari MS, Paiva MM, Marchiori GF. Prevalência de morbidades autorreferidas e fatores associados entre idosos comunitários de Uberaba, Minas Gerais, Brasil. Ciênc. saúde coletiva. 2019;24(9):3305-13. https://doi.org/10.1590/1413-81232018249.31912017. 
3. Jokanovic N, Tan ECK, Dooley MJ, Kirkpatrick CM, Bell JS. Prevalence and factors associated with polypharmacy in long-term care facilities: a systematic review. J Am Med Dir Assoc. 2015;16(6):535.e1-12. http://dx.doi.org/10.1016/j.jamda.2015.03.003. PMid:25869992.

4. Alcântara AO, Camarano AA, Giacomin KC. Política nacional do idoso: velhas e novas questões [Internet]. Rio de Janeiro: IPEA; 2016 [cited 2022 Jan 5]. Available from: https://www.ipea.gov.br/portal/images/stories/PDFs/livros/livros/161006_livro_politica_nacional_id osos.PDF

5. O'Mahony MS, Parbhoo A. Deprescribing in older people. Br J Hosp Med (Lond). 2020;81(1):1-9. http://dx.doi.org/10.12968/hmed.2019.0213. PMid:32003625.

6. Davies LE, Spiers G, Kingston A, Todd A, Adamson J, Hanratty B. Adverse outcomes of polypharmacy in older people: systematic review of reviews. J Am Med Dir Assoc. 2020;21(2):181-7. http://dx.doi.org/10.1016/j.jamda.2019.10.022. PMid:31926797.

7. Gutiérrez-Valencia M, Izquierdo M, Cesari M, Casas-Herrero A, Inzitari M, Martínez-Velilla N. The relationship between frailty and polypharmacy in older people: A systematic review. $\mathrm{Br} \mathrm{J}$ Clin Pharmacol. 2018;84(7):1432-44. http://dx.doi.org/10.1111/bcp.13590. PMid:29575094.

8. World Health Organization. Implementation research in health: a practical guide. Geneva: WHO; 2013.

9. Curran GM, Bauer M, Mittman B, Pyne JM, Stetler C. Effectiveness-implementation Hybrid Designs Combining Elements of Clinical Effectiveness and Implementation Research to Enhance Public Health Impact. Med Care. 2012;50(3):217-26. http://dx.doi.org/10.1097/MLR.0b013e3182408812. PMid:22310560.

10. Pinnock H, et al. Standards for Reporting Implementation Studies (StaRI). Statement BMJ. 2017;356:i6795. http://dx.doi.org/10.1136/bmj.i6795. PMid:28264797.

11. IBM Micromedex® [Internet]. Colorado: IBM Watson Health; 2020 [cited 2021 Oct 19]. Available from: https://www.micromedexsolutions.com

12. By the 2019 American Geriatrics Society Beers Criteria ${ }^{\circledR}$ Update Expert Panel. American Geriatrics Society Beers Criteria ${ }^{\circledR}$ Update Expert Panel. American Geriatrics Society 2019 updated AGS Beers Criteria ${ }^{\circledR}$ for potentially inappropriate medication use in older adults. J Am Geriatr Soc. 2019;67(4):674-94. http://dx.doi.org/10.1111/jgs.15767. PMid:30693946.

13. O'Mahony D, O'Sullivan D, Byrne S, O'Connor MN, Ryan C, Gallagher P. STOPP/START criteria for potentially inappropriate prescribing in older people: version 2. Age Ageing. 2015;44(2):213-8. http://dx.doi.org/10.1093/ageing/afu145. PMid:25324330.

14. Cipolle RJ, Strand LM, Morley PC. Pharmaceutical care practice: the patient centered to medication management. 3rd ed. New York: McGraw-Hill; 2012.

15. Szczepura A, Wild D, Nelson S. Medication administration errors for older people in long-term residential care. BMC Geriatr. 2011;11(82):1-10. http://dx.doi.org/10.1186/1471-2318-11-82. PMid:22151472.

16. Greene SB, Williams CE, Pierson S, Hansen RA, Carey TS. Medication error reporting in nursing homes: identifying targets for patient safety improvement. Qual Saf Health Care. 2010;19(3):21822. http://dx.doi.org/10.1136/qshc.2008.031260. PMid:20123759.

17. Munyisia EN, Yu P, Hailey DM. How nursing staff spend their time on activities in a nursing home: an observational study. J Adv Nurs. 2011;67(9):1908-17. http://dx.doi.org/10.1111/j.13652648.2011.05633.x. PMid:21466577.

18. Qian S, Yu P, Hailey DM, Wang N. Factors influencing nursing time spent on administration of medication in an Australian residential aged care home. J Nurs Manag. 2016;24(3):427-34. http://dx.doi.org/10.1111/jonm.12343. PMid:26691343.

19. Cready CM, Hudson C, Dreyer K. Type of oral solid medication packaging and medication preparation time in nursing homes: a direct observation study. J Clin Pharm Ther. 2017;42(6):710-9. http://dx.doi.org/10.1111/jcpt.12567. PMid:28585405.

20. Forgerini M, Schiavo G, Lucchetta RC, Mastroianni PC. Drug interactions for elderly people with mental and behavioral disorders: a systematic scoping review. Arch Gerontol Geriatr. 2021;93:104283. http://dx.doi.org/10.1016/j.archger.2020.104283. PMid:33227533.

21. Liperoti R, Sganga F, Landi F, Topinkova E, Denkinger MD, van der Roest HG, Foebel AD, FinneSoveri H, Bernabei R, Onder G. Antipsychotic drug interactions and mortality among nursing home 
residents with cognitive impairment. J Clin Psychiatry. 2017;78(1):e76-82.

http://dx.doi.org/10.4088/JCP.15m10303. PMid:28129493.

22. Walsh KA, Dennehy R, Sinnott C, Browne J, Byrne S, McSharry J, Coughlan E, Timmons S. Influences on decision-making regarding antipsychotic prescribing in nursing home residents with dementia: a systematic review and synthesis of qualitative evidence. J Am Med Dir Assoc. 2017;18(10):897.e112. http://dx.doi.org/10.1016/j.jamda.2017.06.032. PMid:28807433.

23. Primary Health Tasmania. Deprescribing resources [cited 2021 Oct 19]. Available from: https://www.primaryhealthtas.com.au/resources/deprescribing-resources/

24. Choosing Wisely Canada. When psychosis isn't the diagnosis: a toolkit for reducing inappropriate use of antipsychotics in long term care. Choosing Wisely Canada. Version 1.2, 2019. [cited 2021 Oct 19]. Available from: https://choosingwiselycanada.org/wpcontent/uploads/2017/07/CWC_Antipsychotics_Toolkit_v1.0_2017-07-12.pdf

25. Riordan PA, Briscoe J, Uritsky TJ, Jones CA, Webb JA. Top ten tips palliative care clinicians should know about psychopharmacology. J Palliat Med. 2019;22(5):572-9. http://dx.doi.org/10.1089/jpm.2019.0106. PMid:30925078.

26. de Lyra DP, Kheir N, Abriata JP, da Rocha CE, Dos Santos CB, Pelá IR. Impact of pharmaceutical care interventions in the identification and resolution of drug-related problems and on quality of life in a group of elderly outpatients in Ribeirão Preto (SP), Brazil. Ther Clin Risk Manag. 2007;3(6):989-98. PMid:18516258.

27. Silva AS, Rocha JA Fo, Bastos LL, Santana DP, Wanderley AG. Acompanhamento farmacoterapêutico em pacientes com dislipidemia em uso de sinvastatina no Componente Especializado de Assistência Farmacêutica: um estudo piloto. Rev Cienc Farm Basica Apl. 2013;34(1):51-7.

\section{Authors' contributions}

All authors of this manuscript participated directly in the planning, execution and writing of this study, in which each author had the following contribution: FASOL and MMGN: Conceptualization, Investigation, Validation, Formal analysis, Writing. CPR, MDS, LRF, SDF, ASAS, SGF and GOB: Investigation, Validation, Formal analysis, Writing, Review, Editing \& Visualization. DRO: Conceptualization, Resources, Writing, Review, Editing, Visualization, Supervision \& Project administration. 